\title{
SELECTION OF MOBILE NETWORK OPERATOR USING THE CRITIC-ARAS METHOD
}

\author{
Sara Bošković ${ }^{1}$ Vesna Radonjić-Djogatović ${ }^{2}$, Predrag Ralević ${ }^{3}$, Momčilo Dobrodolac ${ }^{4}$, \\ Stefan Jovčić ${ }^{5}$ \\ 1,2,4 University of Belgrade, Faculty of Transport and Traffic Engineering, Vojvode Stepe 305, \\ 11000 Belgrade, Serbia \\ ${ }^{3}$ Technical College of Applied Sciences, Uroševac (Leposavić), 24. Novembar bb, 38218 Leposavić, Serbia \\ ${ }^{5}$ University of Pardubice, The Faculty of Transport Engineering, Studentská 95, 53210 Pardubice, Czech Republic
}

Received 23 October 2020; accepted 2 December 2020

\begin{abstract}
Mobile Network Operators play an important role in the communication industry since there are several billions of customers using their services in the world. This paper solves a problem of Mobile Network Operator selection by a user. Therefore, a methodology proposed in this paper is of particular interest from the user's point of view. It can be applied as a decision-making tool that would support a customer in the process of evaluating and choosing a Mobile Network Operators. To rank the available Mobile Network Operators, the authors of this paper consider several criteria identified by the experts. The CRITIC (CRiteria Importance through Inter-criteria Correlation method) finds the importance of the criteria (weights), while the ARAS (Additive Ratio Assessment) method is used for ranking the alternatives and making a decision about the best possible alternative.
\end{abstract}

Keywords: Mobile Network Operator (MNO), multi-criteria decision-making (MCDM), CRITIC method, ARAS method.

\section{Introduction}

It is well known that people have needed to communicate with each other from ancient times. With technology development, communication was possible between more and more remote places, and today it is normal that people communicate wherever they are around the world. Each modern state recognizes the importance of communications. Accordingly, some scope of communication services should be provided to each citizen, regardless of the place of residence, whether it is some remote village or a big city. This type of obligation can be a burden imposed on the operators; however, it also provides some opportunities for making an additional profit (Dobrodolac et al., 2016).

According to Hassan et al. (2013), Mobile Network Operator (MNO) is a telephone company that provides network services for mobile phone users. MNOs play an important role in the communication industry since they connect the population all around the world in a wireless manner and provide a wide variety of communication services. There is a huge number of MNOs globally, which provide services to more than 5 billion users. Strong competition between MNOs

${ }^{4}$ Corresponding author: m.dobrodolac@sf.bg.ac.rs 
in the market is an expected phenomenon. These companies constantly apply some sort of quality improvement measures to be more attractive to customers (Dobrodolac et al., 2014).

Various customers have a different point of view as well as different expectations from the MNOs. The needs and expectations of the customers vary since there are a lot of criteria affecting their decisionmaking process when choosing the MNO. Vijay and Krishnaveni (2016) stated that by knowing the preference and buying behavior of the consumers, the MNOs could develop the promotional method to survive in the competitive market. They also stated that healthy competition between the different MNOs created the mobile number portability, value-added service, voice message, MMS, SMS, unbreakable signals, scheme changes, easy to recharge, other comfortable and satisfactory service to the mobile network customers.

After the discussion with the managers employed in the telecommunication sector, the authors of this paper concluded that three of the most important criteria in evaluating MNOs are related to price, service quality, as well as an appropriate marketing strategy. When the marketing strategy is designed with an aim to gain and attract customers, it leads to an increase in profit as well as a high degree of customer satisfaction.

When there is a task to compare different companies, various methodologies can be applied. For example, when comparing the companies by their efficiency, a Data Envelopment Analysis is a convenient method to use (Ralević et al., 2015; Ralević et al., 2020). Further, some approaches evaluate the success of a company based on employees' well-being (Dobrodolac et al., 2018). However, one of the most popular approaches is related to multi-criteria decision-making (Jovčić et al., 2019).

This paper provides an insight into the implementation of the Multi-Criteria Decision-Making (MCDM) in the field of MNO evaluation and selection. The paper aims to show how the combination of the CRITIC-ARAS methodology can affect the rank of the MNO selection process. According to the authors' knowledge, there are no examples in the literature related to CRITIC-ARAS methodology for the MNO selection.

This article is organized as follows. After we explained the importance of the considered topic in the introduction, in Section 2 the literature review in the field related to MNO is presented. The literature review is separated into illustrative examples as well as the real-life applications, solved by various authors. In our case, the illustrative example was considered. Section 3 relates to the methodological part. This section is divided into two sub-sections. The first subsection explains the CRITIC method for obtaining the criteria weights, while the second one elaborates on the ARAS method for obtaining the final rank of the MNOs. In Section 4, the application of the methodology was carried out on the illustrative example. Section 5 gives concluding remarks and future directions.

\section{Literature Review}

The literature review is performed to provide better insights into the concepts underlying this research. The first part emphasizes 
the application of the ARAS method by various authors that solved the illustrative example problems. The second one includes the papers where the ARAS method was coupled with some other methods applied in real-life studies.

Although the ARAS method is a new approach in the MCDM literature, it has been applied in many areas. Such areas that show the illustrative examples are as follows: logistics center location (Turskis and Zavadskas (2010a)), supplier selection problem (Turskis and Zavadskas (2010b)), foundation installment (Zavadskas et al. (2010)), personnel selection (Keršulienè and Turskis (2014)), and renewable energy systems (Ghenai et al. (2020)). The mentioned research performed by various authors is presented in Table 1 .

Table 1

Application of the ARAS Method in Solving the Illustrative Example Problems

\begin{tabular}{|c|c|c|}
\hline Reference & Illustrative Example Problem & Method(s) \\
\hline Zavadskas and Turskis (2010) & Microclimate in office rooms & ARAS \\
\hline Turskis and Zavadskas (2010a) & Logistics center location & FUZZY-ARAS \\
\hline Turskis and Zavadskas (2010b) & Supplier selection problem & SWARA, FUZZY-ARAS \\
\hline Keršulienė and Turskis (2014) & Personnel selection & SWARA, ARAS \\
\hline Ghenai et al. (2020) & Renewable energy systems & CRITIC-ARAS method \\
\hline Authors' Study & Selection of a Mobile Network Operator &
\end{tabular}

Source: Authors

Note: SWARA - Stepwise Weight Assessment Ratio Analysis

When it comes to real-life applications, the ARAS method was combined with many other MCDM methods. There are several real-life studies where the ARAS method was used, found in the literature (Table 2).

Tupenaite et al. (2010) applied the ARAS method to evaluate alternatives for built and human environment renovation. Baležentis et al. (2012) coupled the ARAS method with the fuzzy logic in order to compare the efficiency of economic sectors in Lithuania. However, Pehlivan and Gürsoy (2019) combined the fuzzy logic with ARAS method to evaluate life satisfaction levels. Fu (2019) utilized an integrated approach to catering supplier selection. A real-live study was performed in the Airline industry. He combined the ARAS method with the
Analytic Hierarchy Process (AHP) in order to obtain the final rank of suppliers. Jovčić et al. (2020) performed a study related to the Freight Distribution Concept (FDC) selection in a tire manufacturing company in the Czech Republic. They used picture fuzzy sets coupled with the ARAS method in order to propose an effective decisionmaking tool. To rank built heritage projects, Turskis et al. (2013) combined the AHP and grey ARAS methods. On the other side, Kutut et al. (2014) used the AHP-ARAS method to rank historic buildings. Zamani et al. (2014) integrated the fuzzy ARAS and ANP methods to solve the brand-extension strategy selection problem. Radović et al. (2018) proposed a rough ARAS method for evaluating the performance parameters of transportation companies. 
Table 2

Application of the ARAS Method Combined with Some Other MCDM Methods in Solving the Real-life Problems

\begin{tabular}{|c|c|c|}
\hline Reference & Real-life Problem & Method(s) \\
\hline Tupenaite et al. (2010) & Built and human environment renovation & $\begin{array}{c}\text { SAW, TOPSIS, } \\
\text { COPRAS and ARAS }\end{array}$ \\
\hline Baležentis et al. (2012) & Economic sector comparison & FUZZY-ARAS \\
\hline Turskis et al. (2013) & Built heritage projects & AHP and GREY ARAS \\
\hline Kutut et al. (2014) & Historic buildings preservation & AHP-ARAS \\
\hline Zamani et al. $(2014)$ & Brand extension strategy selection & FUZZY-ARAS, ANP \\
\hline Radović et al. $(2018)$ & Performance parameters of transportation companies & Rough ARAS \\
\hline Fu (2019) & Catering supplier selection & AHP-ARAS \\
\hline Pehlivan and Gürsoy (2019) & Life satisfaction levels & FUZZY-ARAS \\
\hline Jovčić et al. (2020) & Freight Distribution Concept (FDC) Selection & PICTURE FUZZY -ARAS \\
\hline
\end{tabular}

Note: SAW - Simple Additive Weighting; TOPSIS - Technique for Order of Preference by Similarity to Ideal Solution; COPRAS - Complex Proportional Assessment; ARAS - Additive Ratio Assessment Method; ANP - Analytic Network Process.

The authors' assessment of the literature has revealed that no previous research has been done in the field of MNO selection by applying the CRITIC-ARAS method.

\section{Methodology}

This paper couples two possible methodologies to solve the MNO selection problem. The CRITIC (CRiteria Importance through Inter-criteria Correlation) method is used to find the criteria weights for the mobile network operators. Then, the criteria weights should further be utilized in the ARAS method to select the best MNO. In Section 3.1 the CRITIC method is methodologically elaborated, while Section 3.2 methodologically explains the ARAS method.

\subsection{CRITIC (CRiteria Importance Through Inter-criteria Correlation) Method}

In a decision-making process, the importance of the criteria plays an important role. Not all the criteria are equally important. Many methods exist nowadays for obtaining the criteria weights, where most of them are based on the experts' opinions. In this paper, to evaluate the criteria weights, the authors have decided to use the CRITIC (CRiteria Importance through Inter-criteria Correlation) method. According to Diakoulaki et al. (1995), in the MCDM problems, the CRITIC is an effective method for determining the objective weights of criteria. The obtained criteria weights by this method include both contrast intensity of each criterion and conflict between criteria. According to Ghorabaee et al. (2017), the contrast intensity of criteria is considered by the standard deviation, and conflict between them is measured by the correlation coefficient. The CRITIC method for obtaining the criteria weights may be presented through the following steps:

Step 1 is the calculation of the transformations of performance values $\left(x_{i j}\right)$ and obtaining criteria vectors. It may be presented through 
Equation 1:

$x_{i j}{ }^{T}=\left\{\begin{array}{l}\frac{x_{i j}-x_{j}^{-}}{x_{j}^{*}-x_{j}^{-}} \text {if } j \in B ; \\ \frac{x_{j}^{-}-x_{i j}}{x_{j}^{-}-x_{j}^{*}} \text { if } j \in N ;\end{array}\right.$

Where: $x_{i j}{ }^{T}$ presents the transformed value, $x_{j}$ presents the vector of $j$-th criterion, $x_{j}^{*}$ and $x_{j}^{-}$presents the ideal and anti-ideal values with respect to $j$-th criterion. If $j \in B$ then $x_{j}^{*}=\max _{i} x_{i j}$ and $x_{j}^{-}=\min _{i} x_{i j}$. If $j \epsilon N$ then $x_{j}^{*}$ $=\min _{i} x_{i j}$ and $x_{j}^{-}=\max _{i} x_{i j}$.

In Step 2, the standard deviation $\delta_{j}$ of each criterion is calculating using the corresponding vector.

Step 3 formulates a $m x m$ square matrix $R$ with elements $r_{j k}$, where $k=1,2, \ldots, m$.

$R=\left[r_{j k}\right]_{m x m}$

The elements of this matrix are the linear correlation coefficient between the vectors $x_{j}$ and $x_{k}$.

In Step 4, the information measure of each criterion is calculated by applying the equation (3):

$H_{j}=\delta_{j} \sum_{k=1}^{m}\left(1-r_{j k}\right)$

Step 5 is the final step and the criteria weights are calculating here by applying the equation (4):

$W_{j}=\frac{H_{j}}{\sum_{k=1}^{m} H_{k}}$

\subsection{The Additive Ratio Assessment (ARAS) Method}

The Additive Ratio Assessment (ARAS) method is one of the relatively new multicriteria decision-making methods developed by Zavadskas and Turskis (2010). This method is very efficient and easy to use in situations where multiple criteria are taken into consideration. According to Zavadskas and Turskis (2010), the ARAS method can be described through several steps:

Step 1. Formulate a Decision-making Matrix (DMM)

A decision-making matrix consists of $m$ feasible alternatives (rows) rated on $\mathrm{n}$ sign full criteria (columns).

$X=\left[\begin{array}{ccccc}x_{01} & \cdots & x_{0 j} & \cdots & x_{0 n} \\ \vdots & \ddots & \vdots & \ddots & \vdots \\ x_{i 1} & \cdots & x_{i j} & \cdots & x_{i n} \\ \vdots & \ddots & \vdots & \ddots & \vdots \\ x_{m 1} & \cdots & x_{m j} & \cdots & x_{m n}\end{array}\right] ; i=\overline{0, m}, j=\overline{1, n}$

where: $m$ - number of alternatives, $n$ - number of criteria describing each alternative, $x_{i j}$ value representing the performance value of the $i$-th alternative in terms of the $j$-th criterion, $x_{0 j}$ - optimal value of $j$-th criterion.

If the optimal value of $j$-th criterion is unknown, then:

$x_{0 j}=\max _{i} x_{i j}$, if $\max _{i} x_{i j}$ is preferable;

$x_{0 j}=\min _{i} x_{i j}^{*}$, if $\min _{i} x_{i j}^{*}$ is preferable;

Usually, the performance values $x_{i j}$ and the criteria weights $W_{j}$ are considered as the entries of a DMM. The system of criteria as well as values and initial weights of criteria is determined by experts. The information can be corrected by the interested parties by taking into account their goals and opportunities.

Step 2. Normalize the Input Data

In this step, the initial values of all the criteria are normalized - defining values $\overline{x_{i j}}$ of normalized decision-making matrix $\bar{X}$. 
$\bar{X}=\left[\begin{array}{ccccc}\bar{x}_{01} & \cdots & \bar{x}_{0 j} & \cdots & \bar{x}_{0 n} \\ \vdots & \ddots & \vdots & \ddots & \vdots \\ \bar{x}_{i 1} & \cdots & \bar{x}_{i j} & \cdots & \bar{x}_{i n} \\ \vdots & \ddots & \vdots & \ddots & \vdots \\ \bar{x}_{m 1} & \cdots & \bar{x}_{m j} & \cdots & \bar{x}_{m n}\end{array}\right] ; i=\overline{0, m}, j=\overline{1, n} ;$

For the criteria with the maximal preferable values, the normalization is done by the following equation:

$\overline{x_{l \jmath}}=\frac{x_{i j}}{\sum_{i=0}^{m} x_{i j}}$

For the criteria with the minimal preferable values, the normalization is done through two-steps, by the following equation:

$x_{i j}=\frac{1}{x_{i j}^{*}} ; \overline{x_{\imath j}}=\frac{x_{i j}}{\sum_{i=0}^{m} x_{i j}}$

Step 3. Define Normalized-weighted Matrix - $\widehat{X}$

It is possible to evaluate the criteria with weights $0<\mathrm{W}_{\mathrm{j}}<1$. Only well-founded weights should be used because weights are always subjective and influence the solution. The values of weight $\mathrm{W}_{\mathrm{j}}$ are usually determined by the expert evaluation method. The sum of weights $W_{j}$ is limited as follows:

$\sum_{j=1}^{n} w_{j}=1$

$\hat{X}=\left[\begin{array}{ccccc}\hat{x}_{01} & \cdots & \hat{x}_{0 j} & \cdots & \hat{x}_{0 n} \\ \vdots & \ddots & \vdots & \ddots & \vdots \\ \hat{x}_{i 1} & \cdots & \hat{x}_{i j} & \cdots & \hat{x}_{i n} \\ \vdots & \ddots & \vdots & \ddots & \vdots \\ \hat{x}_{m 1} & \cdots & \hat{x}_{m j} & \cdots & \hat{x}_{m n}\end{array}\right] ; i=\overline{0, m}, j=\overline{1, n}$

Normalized-weighted values of all the criteria are calculated as follows:

$\hat{x}_{i j}=\bar{x}_{i j} \cdot \mathrm{W}_{\mathrm{j}} ; i=\overline{0, m}$

Where $\mathrm{W}_{\mathrm{j}}$ is the weight (importance) of the $j$-th criterion and $\bar{x}_{i j}$ is the normalized rating of the $\mathrm{j}$-th criterion.
Step 4. Determine the Value of Optimality Function

$S_{i}=\sum_{j=1}^{n} \hat{x}_{i j} ; i=\overline{0, m}$

Where: $S_{i}$ is the value of optimality function of $i$-th alternative.

The biggest value of $S_{i}$ is the best one, while the least one is the worst. Therefore, the greater the value of the optimality function $S_{i}$, the more effective the alternative. The priorities of alternatives can be determined according to the value $S_{i}$.

Step 5. Calculate the Degree of the Alternative Utility

To calculate the degree of the alternative utility, it is necessary to compare the variants with the ideally best one $S_{0}$. The calculation of the utility degree $K_{i}$ of an alternative $a_{i}$ is given in Equation (14):

$K_{i}=\frac{s_{i}}{s_{0}} ; i=0, m$

Where $S_{i}$ and $S_{0}$ are the optimality criterion values, obtained from Equation (13). The calculated values $K_{i}$ are between 0 and 1 .

\section{Application of the Methodology to an Illustrative Example}

In this section, the CRITIC-ARAS methodology is applied to an MNO selection problem. This paper aims to offer customers a decision-making tool when choosing the best possible alternative (MNO) among several of them. To solve this problem, two of the methodologies are proposed. The first one (Critic method) is applied to determine the criteria weights since not all the criteria are equally important. The second one is 
the ARAS method, and it is used to rank the MNOs.

Since this is a multi-criteria decision-making problem, several criteria (determined by the experts from the telecommunication field) are taken into consideration. Those criteria are as follows: Call price $\left(\mathrm{C}_{1}\right)$, Network quality $\left(\mathrm{C}_{2}\right)$, Geographical coverage $\left(\mathrm{C}_{3}\right)$, SMS price $\left(\mathrm{C}_{4}\right)$, Security \& Data protection $\left(C_{5}\right)$ as well as Value-added services $\left(C_{6}\right)$ :

- $\quad$ Call price $\left(\mathrm{C}_{1}\right)$ - this criterion represents a cost that customer pays for the call by using the services of the considered MNO. The call price is expressed in Euros per minute.

- Network quality $\left(\mathrm{C}_{2}\right)$ - this criterion is given between the intervals from zero to one, where 0 represents the poorest network quality while 1 represents the highest quality network.

- Geographical coverage $\left(\mathrm{C}_{3}\right)$-indicates the percentage of the territory of the country covered by a particular MNO.

- $\quad$ SMS price $\left(\mathrm{C}_{4}\right)$ - this represents the cost customer pays when sending messages by using service by a particular MNO.
- Security \& Data protection $\left(\mathrm{C}_{5}\right)$ this criterion is expressed between the intervals from zero to one, where 1 represents the highest security of a particular MNO.

- Value-added services $\left(C_{6}\right)$ - denote the number of additional services that a particular MNO provides besides the essential ones.

When it comes to MNOs, there are four possible alternatives taken into consideration. They are marked as Mobile Network Operator 1 (MNO1), Mobile Network Operator 2 (MNO2), Mobile Network Operator 3 (MNO3) as well as Mobile Network Operator 4 (MNO4).

\subsection{Application of the CRITIC Method to Obtain the Criteria Weights}

To obtain the criteria weights, the first step is to formulate an initial decision-making matrix. This matrix gives the data about all the possible alternatives compared through the 6 previously mentioned criteria. The initial decision-making matrix is presented in Table 3.

Table 3

The Initial Decision-making Matrix

\begin{tabular}{|c|c|c|c|c|c|c|}
\hline Mobile Network Operator & $\mathbf{C}_{\mathbf{1}}$ & $\mathbf{C}_{\mathbf{2}}$ & $\mathbf{C}_{\mathbf{3}}$ & $\mathbf{C}_{\mathbf{4}}$ & $\mathbf{C}_{\mathbf{5}}$ & $\mathbf{C}_{\mathbf{6}}$ \\
\hline MNO1 & 0.58 & 0.88 & 99.98 & 0.22 & 0.5 & 5 \\
\hline MNO2 & 0.62 & 0.92 & 98.88 & 0.25 & 0.6 & 7 \\
\hline MNO3 & 0.6 & 0.89 & 94.99 & 0.27 & 0.5 & 8 \\
\hline MNO4 & 0.59 & 0.94 & 97.66 & 0.23 & 0.6 & 6 \\
\hline Non Beneficial/ Beneficial & $\mathrm{N}$ & $\mathrm{B}$ & $\mathrm{B}$ & $\mathrm{N}$ & $\mathrm{B}$ & $\mathrm{B}$ \\
\hline Best Value & 0.58 & 0.94 & 99.98 & 0.22 & 0.6 & 8 \\
\hline Worst Value & 0.62 & 0.88 & 94.99 & 0.27 & 0.5 & 5 \\
\hline
\end{tabular}

The next step is the calculation of the transformations of performance values $\left(x_{i j}\right)$ and calculation of the standard deviation $\delta_{j}$ of each criterion. It is shown in Table 4. 


\section{Table 4}

Transformations of Performance Values and Standard Deviation $\delta$

\begin{tabular}{|c|c|c|c|c|c|c|}
\hline & $\mathbf{C}_{1}$ & $\mathbf{C}_{\mathbf{2}}$ & $\mathbf{C}_{3}$ & $\mathbf{C}_{4}$ & $\mathbf{C}_{5}$ & $\mathbf{C}_{6}$ \\
\hline MNO1 & 1.0000 & 0.0000 & 1.0000 & 1.0000 & 0.0000 & 0.0000 \\
\hline MNO2 & 0.0000 & 0.6667 & 0.7796 & 0.4000 & 1.0000 & 0.6667 \\
\hline MNO3 & 0.5000 & 0.1667 & 0.0000 & 0.0000 & 0.0000 & 1.0000 \\
\hline MNO4 & 0.7500 & 1.0000 & 0.5351 & 0.8000 & 1.0000 & 0.3333 \\
\hline$\delta_{j}$ & 0.42696 & 0.45896 & 0.42997 & 0.44347 & 0.57735 & 0.43033 \\
\hline
\end{tabular}

Table 5 represents $m x m$ square matrix (R) formulated from the six chosen criteria.

\section{Table 5}

Formulated mxm Square Matrix from the Six Criteria

\begin{tabular}{|c|c|c|c|c|c|c|}
\hline & $\mathbf{C}_{\mathbf{1}}$ & $\mathbf{C}_{\mathbf{2}}$ & $\mathbf{C}_{\mathbf{3}}$ & $\mathbf{C}_{\mathbf{4}}$ & $\mathbf{C}_{5}$ & $\mathbf{C}_{\mathbf{6}}$ \\
\hline $\mathbf{C}_{\mathbf{1}}$ & 1.0000 & -0.3367 & 0.1803 & 0.6382 & -0.5071 & -0.6803 \\
\hline $\mathbf{C}_{\mathbf{2}}$ & -0.3367 & 1.0000 & -0.0103 & 0.0955 & 0.9435 & 0.0469 \\
\hline $\mathbf{C}_{\mathbf{3}}$ & 0.1803 & -0.0103 & 1.0000 & 0.8161 & 0.2112 & -0.8273 \\
\hline $\mathbf{C}_{\mathbf{4}}$ & 0.6382 & 0.0955 & 0.8161 & 1.0000 & 0.1302 & -0.9898 \\
\hline $\mathbf{C}_{\mathbf{5}}$ & -0.5071 & 0.9435 & 0.2112 & 0.1302 & 1.0000 & 0.0000 \\
\hline $\mathbf{C}_{\mathbf{6}}$ & -0.6803 & 0.0469 & -0.8273 & -0.9898 & 0.0000 & 1.0000 \\
\hline
\end{tabular}

The information measure of each criterion $\left(H_{j}\right)$, as well as the criteria weights $(\mathrm{Wj})$, are calculated by applying the Equations (3) and
(4). It is highlighted in Table 6. For better clarification, the obtained criteria weights are presented in Figure 1.

\section{Table 6}

Obtained Information Measure of each Criterion $\left(H_{j}\right)$ as well as the Criteria Weights $\left(W_{j}\right)$

\begin{tabular}{|c|c|c|c|c|c|c|c|c|c|c|}
\hline & $\mathbf{C 1}$ & $\mathbf{C 2}$ & $\mathbf{C 3}$ & $\mathbf{C 4}$ & $\mathbf{C 5}$ & $\mathbf{C 6}$ & Sum by Rows & $\delta_{j}$ & $\boldsymbol{H}_{j}$ & $\boldsymbol{W}_{j}$ \\
\hline C1 & 0.0000 & 1.3367 & 0.8197 & 0.3618 & 1.5071 & 1.6803 & 5.7056 & 0.4270 & 2.4360 & 0.1748 \\
\hline C2 & 1.3367 & 0.0000 & 1.0103 & 0.9045 & 0.0565 & 0.9531 & 4.2611 & 0.4590 & 1.9557 & 0.1403 \\
\hline C3 & 0.8197 & 1.0103 & 0.0000 & 0.1839 & 0.7888 & 1.8273 & 4.6300 & 0.4300 & 1.9908 & 0.1428 \\
\hline C4 & 0.3618 & 0.9045 & 0.1839 & 0.0000 & 0.8698 & 1.9898 & 4.3098 & 0.4435 & 1.9113 & 0.1371 \\
\hline C5 & 1.5071 & 0.0565 & 0.7888 & 0.8698 & 0.0000 & 1.0000 & 4.2222 & 0.5774 & 2.4377 & 0.1749 \\
\hline C6 & 1.6803 & 0.9531 & 1.8273 & 1.9898 & 1.0000 & 0.0000 & 7.4506 & 0.4303 & 3.2062 & 0.2300 \\
\hline
\end{tabular}

From Table 6, it may be noticed that the highest importance is assigned to the value-added services $(0.23)$, followed by the security \& data protection (0.1749), call price (0.1748), geographical coverage (0.1428), network quality (0.1403) and SMS price $(0.1371)$, respectively. 


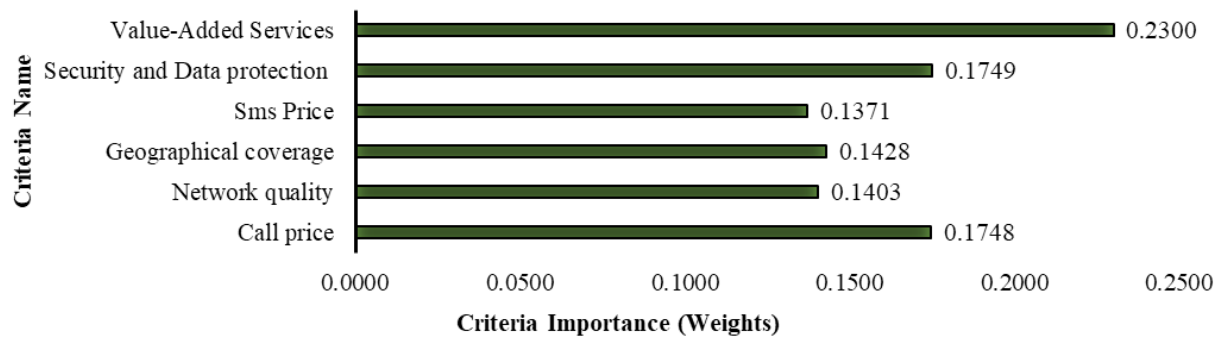

Fig. 1.

The Obtained Rank of the Criteria Weights

The obtained criteria weights use the ARAS method to rank the MNOs.

\subsection{Application of the ARAS Method to Obtain the Rank of Mobile Network Operators}

The second part of this paper relates to the application of the ARAS method. This method uses the criteria weights obtained from the CRITIC method.

The initial decision-making matrix is presented in Table 7.

\section{Table 7}

The Initial Decision-making Matrix

\begin{tabular}{|c|c|c|c|c|c|c|}
\hline & $\begin{array}{c}\text { Call Price } \\
\text { (Euro/min) }\end{array}$ & $\begin{array}{c}\text { Network } \\
\text { Quality }\end{array}$ & $\begin{array}{c}\text { Geographical } \\
\text { Coverage }\end{array}$ & $\begin{array}{c}\text { SMS Price } \\
\text { (Euro /SMS) }\end{array}$ & $\begin{array}{c}\text { Security } \\
\text { \& Data } \\
\text { Protection }\end{array}$ & $\begin{array}{c}\text { Value- } \\
\text { added } \\
\text { Services }\end{array}$ \\
\hline 0 - Optimal Value & 0.58 & 0.94 & 99.98 & 0.22 & 0.6 & 8 \\
\hline MNO1 & 0.58 & 0.88 & 99.98 & 0.22 & 0.6 & 5 \\
\hline MNO2 & 0.62 & 0.92 & 98.88 & 0.25 & 0.6 & 7 \\
\hline MNO3 & 0.6 & 0.89 & 94.99 & 0.27 & 0.5 & 8 \\
\hline MNO4 & 0.59 & 0.94 & 97.66 & 0.23 & 0.6 & 6 \\
\hline C/B & C & B & B & C & B & B \\
\hline Weights & 0.1748 & 0.1403 & 0.1428 & 0.1371 & 0.1749 & 0.2300 \\
\hline Sum & 8.42 & 4.57 & 491.49 & 21.14 & 2.80 & 34.00 \\
\hline
\end{tabular}


The next step is normalization of the input data and it is presented in Table 8.

Table 8

Normalization of the Initial Decision-making Matrix

\begin{tabular}{|c|c|c|c|c|c|c|}
\hline & $\mathbf{C}_{\mathbf{1}}$ & $\mathbf{C}_{\mathbf{2}}$ & $\mathbf{C}_{\mathbf{3}}$ & $\mathbf{C}_{\mathbf{4}}$ & $\mathbf{C}_{\mathbf{5}}$ & $\mathbf{C}_{\mathbf{6}}$ \\
\hline Optimal Value - 0 & 0.2047 & 0.2057 & 0.2034 & 0.2150 & 0.2143 & 0.2353 \\
\hline MNO1 & 0.2047 & 0.1926 & 0.2034 & 0.2150 & 0.2143 & 0.1471 \\
\hline MNO2 & 0.1915 & 0.2013 & 0.2012 & 0.1892 & 0.1786 & 0.2059 \\
\hline MNO3 & 0.1979 & 0.1947 & 0.1933 & 0.1752 & 0.2143 & 0.2353 \\
\hline MNO4 & 0.2012 & 0.2057 & 0.1987 & 0.2056 & 0.1786 & 0.1765 \\
\hline C/B & C & B & B & C & B & B \\
\hline Weights & 0.1748 & 0.1403 & 0.1428 & 0.1371 & 0.1749 & 0.2300 \\
\hline
\end{tabular}

The normalized weighted values $\left(\hat{x}_{i j}\right)$, the value of optimality function $\left(S_{i}\right)$ as well as the degree of the alternative utility $\left(K_{i}\right)$ presented in Table 9.

Table 9

Normalized Weighted Values $\left(\hat{x}_{i j}\right)$, Value of Optimality Function $\left(S_{i}\right)$ and the Degree of the Alternative $\operatorname{Utility}\left(K_{i}\right)$

\begin{tabular}{|c|c|c|c|c|c|c|c|c|c|}
\hline & C1 & C2 & C3 & C4 & C5 & C6 & S $_{\mathbf{i}}$ & $\mathbf{K}_{i}$ & Rank \\
\hline Optimal value - 0 & 0.0358 & 0.0289 & 0.0290 & 0.0295 & 0.0375 & 0.0541 & 0.2148 & & \\
\hline MNO1 & 0.0358 & 0.0270 & 0.0290 & 0.0295 & 0.0375 & 0.0338 & 0.1926 & 0.8969 & $\mathbf{3 .}$ \\
\hline MNO2 & 0.0335 & 0.0282 & 0.0287 & 0.0259 & 0.0312 & 0.0474 & 0.1950 & 0.9078 & $\mathbf{2 .}$ \\
\hline MNO3 & 0.0346 & 0.0273 & 0.0276 & 0.0240 & 0.0375 & 0.0541 & 0.2051 & 0.9551 & $\mathbf{1 .}$ \\
\hline MNO4 & 0.0352 & 0.0289 & 0.0284 & 0.0282 & 0.0312 & 0.0406 & 0.1924 & 0.8960 & $\mathbf{4 .}$ \\
\hline
\end{tabular}

Figure 2 presents better clarification of the obtained degree of the alternative utility (final rank of the $\mathrm{MNO}$ ).

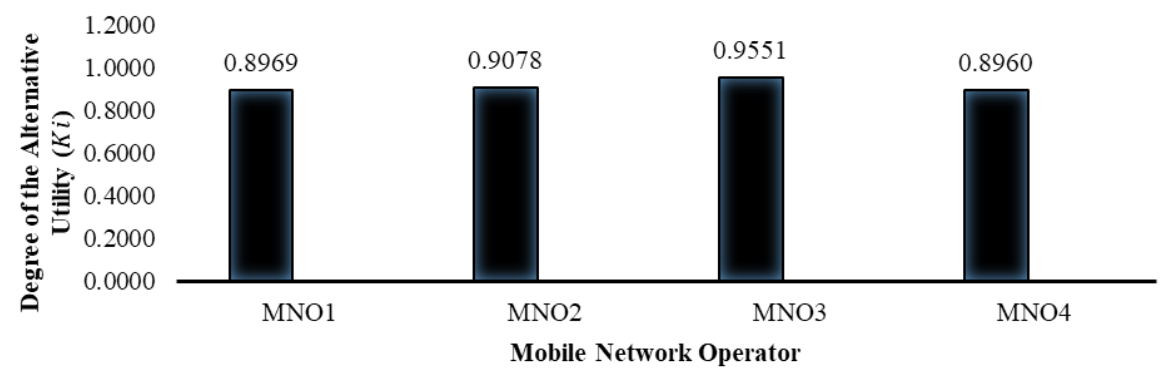

Fig. 2.

The Rank of the Mobile Network Operators according to the Degree of the Alternative Utility 
The results obtained from the ARAS method shows that the best Mobile Network Operator is the MNO3, with the degree of utility 0.9551, followed by the MNO2 (0.9078), MNO1 (0.8969) and MNO4 (0.8960).

\section{Conclusion}

In this article, the study on the Mobile Network Operator selection problem was carried out. Two methods are coupled in order to obtain the desired result. The first method was the CRITIC method, and it was used to determine the criteria weights. The second one was the ARAS method, used to rank the best of four possible alternatives.

The issue of the MNOs is of crucial importance nowadays, and in the future, it will have an increasing trend. While selecting the MNO, from the customer's point of view, many criteria should be taken into consideration. Among many of them, special attention should be played on price, network quality as well as valueadded services. As the authors emphasized in the introduction, good marketing strategies should help telecommunication companies to gain new customers, as well as to retain the existing ones.

By applying the proposed methodology, regarding the criteria weights, the following conclusion has been reached: the highest importance was assigned to the value-added services $(0.23)$, followed by the security \& data protection (0.1749), call price (0.1748), geographical coverage $(0.1428)$, network quality (0.1403) and SMS price (0.1371), respectively. When those criteria weights were taken into consideration, and after the ARAS method was applied, the following rank was reached: the best Mobile Network
Operator was the MNO3, with the degree of utility 0.9551 , followed by the MNO2 (0.9078), MNO1 (0.8969) and MNO4 (0.8960).

The combination of those two methodologies proved to be very effective when deciding about the Mobile Network Operator selection process. The future direction of this paper can be to solve the problem with a similar approach by combining some other multi-criteria decision-making methods, fuzzy logic, etc. We believe the implemented research could be an inspiration for other authors to investigate the considered telecommunication topic.

\section{References}

Baležentis, A.; Baležentis, T.; Misiūnas, A. 2012. Integrated assessment of Lithuanian economic sectors based on financial ratios and fuzzy MCDM Methods, Technological and Economic Development of Economy 18(1): 34-53. https://doi.org/10.3846/20294913.2012.656151.

Diakoulaki, D.; Mavrotas, G.; Papayannakis, L. 1995. Determining objective weights in multiple criteria problems: the critic method, Computers \& Operations Research 22(7): 763-770. https://doi.org/10.1016/03050548(94)00059-h.

Dobrodolac, M.; Ralević, P.; Švadlenka, L.; Radojičić, V. 2016. Impact of a new concept of universal service obligations on revenue increase in the Post of Serbia, Promet - Traffic and Transportation 28(3): 235-244. http:// dx.doi.org/10.7307/ptt.v28i3.1835.

Dobrodolac, M.; Marković, D.; Čubranić-Dobrodolac, M.; Denda, N. 2014. Using work stress measurement to develop and implement a TQM programme: a case of counter clerks in Serbian Post, Total Quality Management and Business Excellence 25(11-12): 1262-1279. https://doi. org/10.1080/14783363.2012.704280. 
Dobrodolac, M.; Švadlenka, L.; Čubranić-Dobrodolac, M.; Čičević, S.; Stanivuković, B. 2018. A model for the comparison of business units, Personnel Review 47(1): 150-165. https://doi.org/10.1108/PR-02-2016-0022.

Fu, Y.-K. 2019. An integrated approach to catering supplier selection using AHP-ARAS-MCGP methodology, Journal of Air Transport Management 75: 164169. https://doi.org/10.1016/j.jairtraman.2019.01.011.

Ghenai, C.; Albawab, M.; Bettayeb, M. 2020. Sustainability indicators for renewable energy systems using multi-criteria decision-making model and extended SWARA/ARAS hybrid method, Renewable Energy 146: 580-597. https://doi.org/10.1016/j.renene.2019.06.157.

Ghorabaee, K. M.; Amiri, M.; Zavadskas, E. K.; Antuchevičienè, J. 2017. Assessment of third-party logistics providers using a CRITIC-WASPAS approach with interval type-2 fuzzy sets, Transport 32(1): 66-78. https://doi.org/10.3846/16484142.2017.1282381.

Hassan, N.; Ahmad, N.; Malissa-Aminuddin, W. 2013. Selection of Mobile Network Operator Using Analytic Hierarchy Process (AHP), Advances in Natural and Applied Sciences 7(1): 1-5.

Jovčić, S.; Průša, P.; Dobrodolac, M.; Švadlenka, L. 2019. A Proposal for a Decision-Making Tool in Third-Party Logistics (3PL) Provider Selection Based on MultiCriteria Analysis and the Fuzzy Approach, Sustainability 11(15): 4236. https://doi.org/10.3390/su11154236.

Jovčić, S.; Simić, V.; Průša, P.; Dobrodolac, M. 2020. Picture Fuzzy ARAS Method for Freight Distribution Concept Selection, Symmetry 12(7): 1062. https://doi. org/10.3390/sym 12071062 .

Keršulienè, V.; Turskis, Z. 2014. A hybrid linguistic fuzzy multiple criteria group selection of a chief accounting officer, Journal of Business Economics and Management 15(2): 232-252. https://doi.org/10.3846/16111699. 2014.903201 .
Kutut, V.; Zavadskas, E.K.; Lazauskas, M. 2014. Assessment of priority alternatives for preservation of historic buildings using model based on ARAS and AHP methods, Archives of Civil and Mechanical Engineering 14(2): 287-294. https://doi.org/10.1016/j.acme.2013.10.007.

Pehlivan, N.Y.; Gürsoy, Z. 2019. Determination of individuals' life satisfaction levels living in Turkey by FMCDM methods, Kybernetes 48(8): 1871-1893. https:// doi.org/10.1108/K-04-2018-0184.

Radović, D.; Stević, Ž.; Pamučar, D.; Zavadskas, E.K.; Badi, I.; Antuchevičiene, J.; Turskis, Z. 2018. Measuring performance in transportation companies in developing countries: A novel rough ARAS Model, Symmetry 10(10): 434. https://doi.org/10.3390/sym 10100434.

Ralević, P.; Dobrodolac, M.; Marković, D.; Mladenović, S. 2015. The Measurement of Public Postal Operators' Profit Efficiency by Using Data Envelopment Analysis (DEA): a Case Study of the European Union Member States and Serbia, Engineering Economics 26(2): 159-168. http://dx.doi.org/10.5755/j01.ee.26.2.3360.

Ralević, P.; Dobrodolac, M.; Švadlenka, L.; Šarac, D.; Đurić, D. 2020. Efficiency and productivity analysis of universal service obligation: a case of 29 designated operators in the European countries, Technological and Economic Development of Economy 26(4): 785-807. https:// doi.org/10.3846/tede.2020.12062.

Tupenaite, L.; Zavadskas, E.K.; Kaklauskas, A.; Turskis, Z.; Seniut, M. 2010. Multiple criteria assessment of alternatives for built and human environment renovation, Journal of Civil Engineering and Management 16(2): 257-266. https://doi.org/10.3846/jcem.2010.30.

Turskis, Z.; Zavadskas, E.K. 2010a. A new fuzzy additive ratio assessment method (ARAS-F). Case study: The analysis of fuzzy multiple criteria in order to select the logistic centers location, Transport 25(4): 423-432. https://doi.org/10.3846/transport.2010.52. 
Turskis, Z.; Zavadskas, E.K. 2010b. A novel method for multiple criteria analysis: Grey Additive Ratio Assessment (ARAS-G) method, Informatica 21(4): 597-610. http://dspace.vgtu.lt/handle/1/2036.

Turskis, Z.; Zavadskas, E.K.; Kutut, V. 2013. A model based on ARAS-G and AHP methods for multiple criteria prioritizing of heritage value, International Journal of Information Technology \& Decision Making 12(1): 45-73. https://doi.org/10.1142/S021962201350003X.

Vijay, P.; Krishnaveni, V. 2016. Customer preferences towards the mobile network service provider- a study with the special reference to Coimbatore city, International Journal of Management Research \& Review 6(10): 1386-1392.
Zamani, M.; Rabbani, A.; Yazdani-Chamzini, A.; Turskis, Z. 2014. An integrated model for extending brand based on fuzzy ARAS and ANP methods, Journal of Business Economics and Management 15(3): 403-423. https://doi.org/10.3846/16111699.2014.923929.

Zavadskas, E.K.; Turskis, Z. 2010. A new additive ratio assessment (ARAS) method in multi-criteria decisionmaking, Technological and Economic Development of Economy 16(2): 159-172. https://doi.org/10.3846/tede.2010.10. 